\title{
Regioselective synthesis of $\eta^{4}$-dienylphosphane ruthenium complexes by oxidative coupling reactions
}

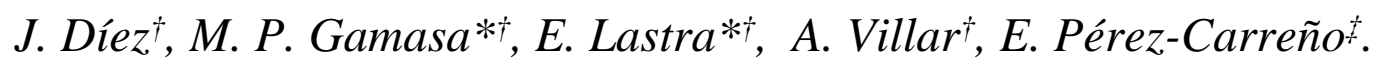

Supporting Information:

${ }^{1} \mathrm{H},{ }^{31} \mathrm{P}\left\{{ }^{1} \mathrm{H}\right\}$ and ${ }^{13} \mathrm{C}\left\{{ }^{1} \mathrm{H}\right\}$ NMR spectra for complexes $\mathbf{1}, \mathbf{3}, \mathbf{4}, \mathbf{5}$ and $\mathbf{6}$ 


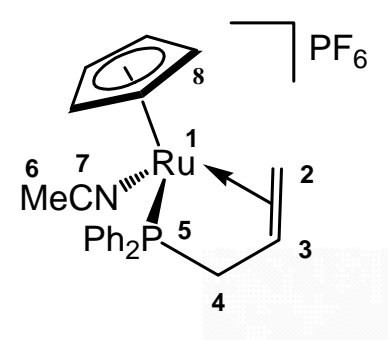

Complex 1
${ }^{31} \mathrm{P}\left\{{ }^{1} \mathrm{H}\right\}$ NMR $\left(121.5 \mathrm{MHZ}, \mathrm{CD}_{2} \mathrm{Cl}_{2}, 18{ }^{\circ} \mathrm{C}\right)$

P5

P5

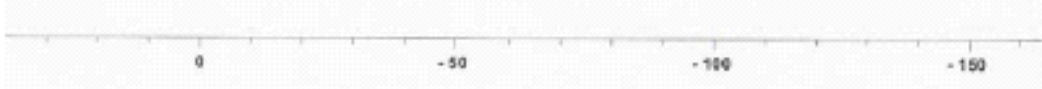

${ }^{1} \mathrm{H}$ NMR (300.1 MHZ, $\left.\mathrm{CD}_{2} \mathrm{Cl}_{2}, 18^{\circ} \mathrm{C}\right)$
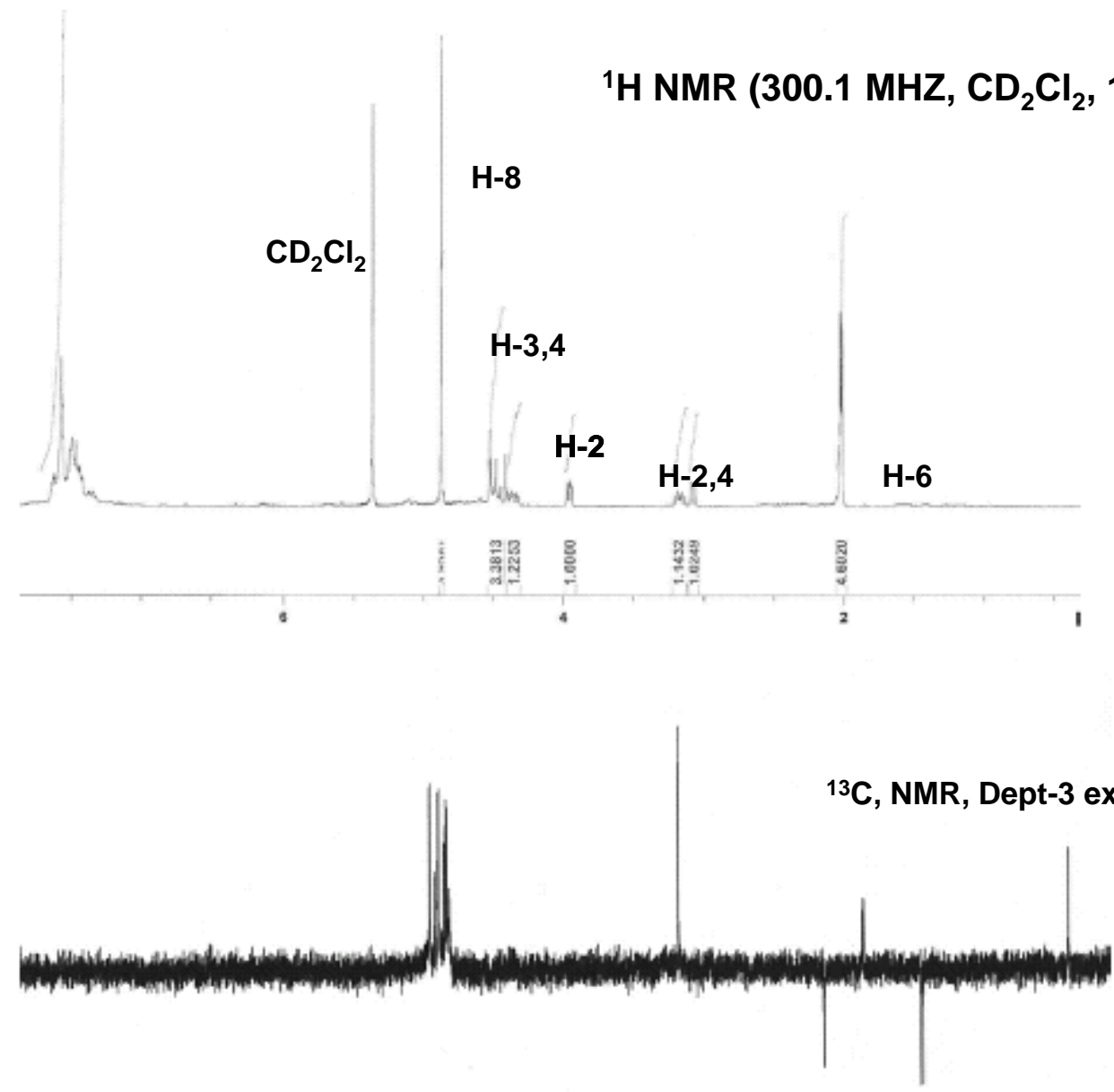

$\begin{array}{lllllllllll}200 & 180 & 160 & 140 & 120 & 100 & 80 & 60 & 40 & 20 & \text { ppm }\end{array}$ 


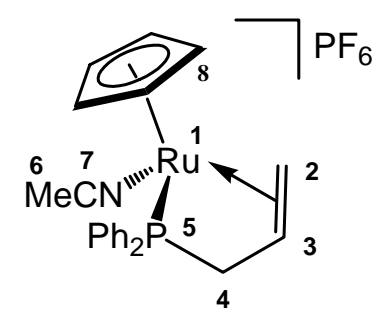

Complex 1

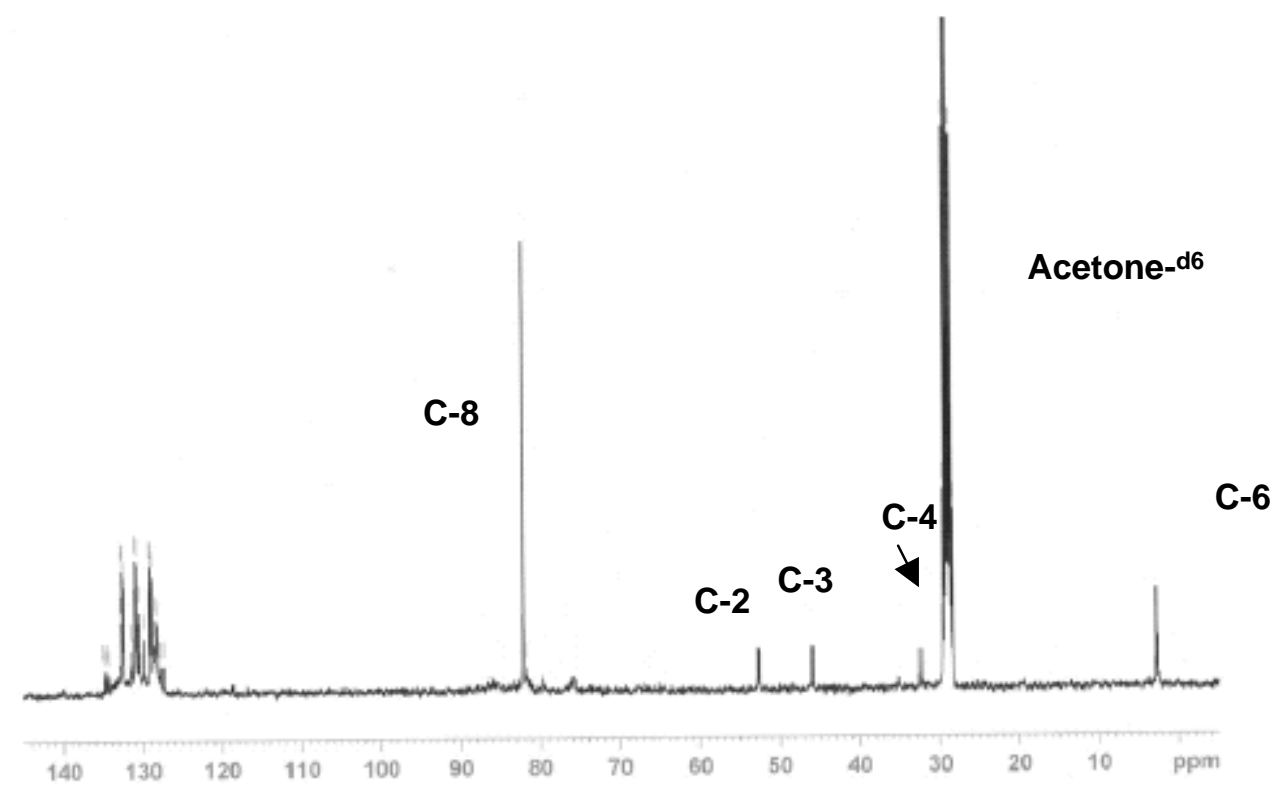




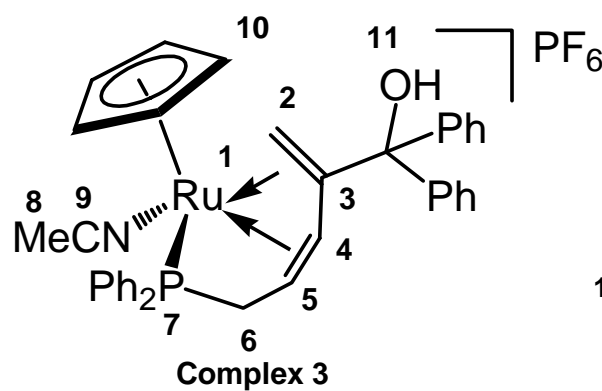

${ }^{1} \mathrm{H}$ NMR (300.1 MHZ, acetone- $\left.\mathrm{d}_{6}, 1^{\circ}{ }^{\circ} \mathrm{C}\right)$

Complex 3
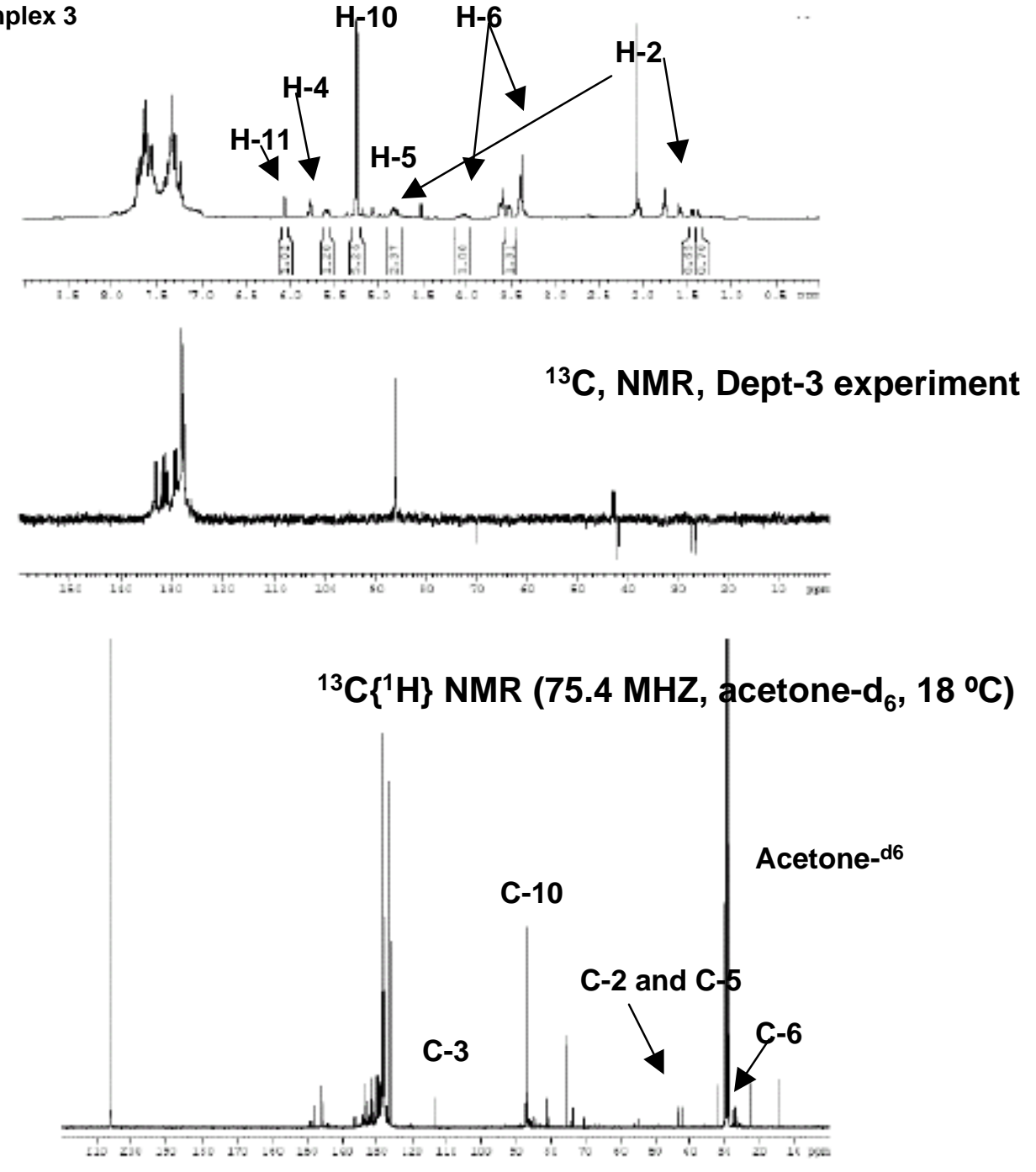


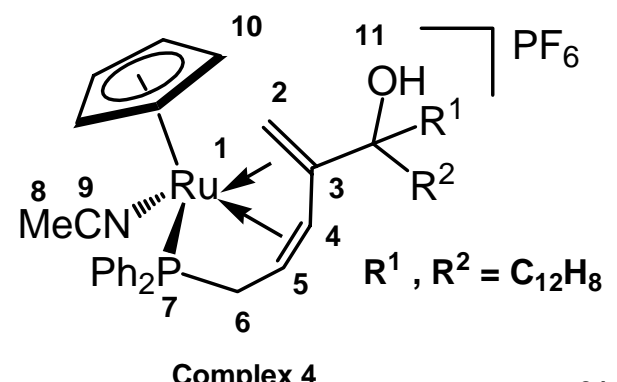

${ }^{31} \mathrm{P}\left\{{ }^{1} \mathrm{H}\right\}$ NMR (121.5 MHZ, acetone- $\left.\mathrm{d}_{6}, 18{ }^{\circ} \mathrm{C}\right)$

P-7

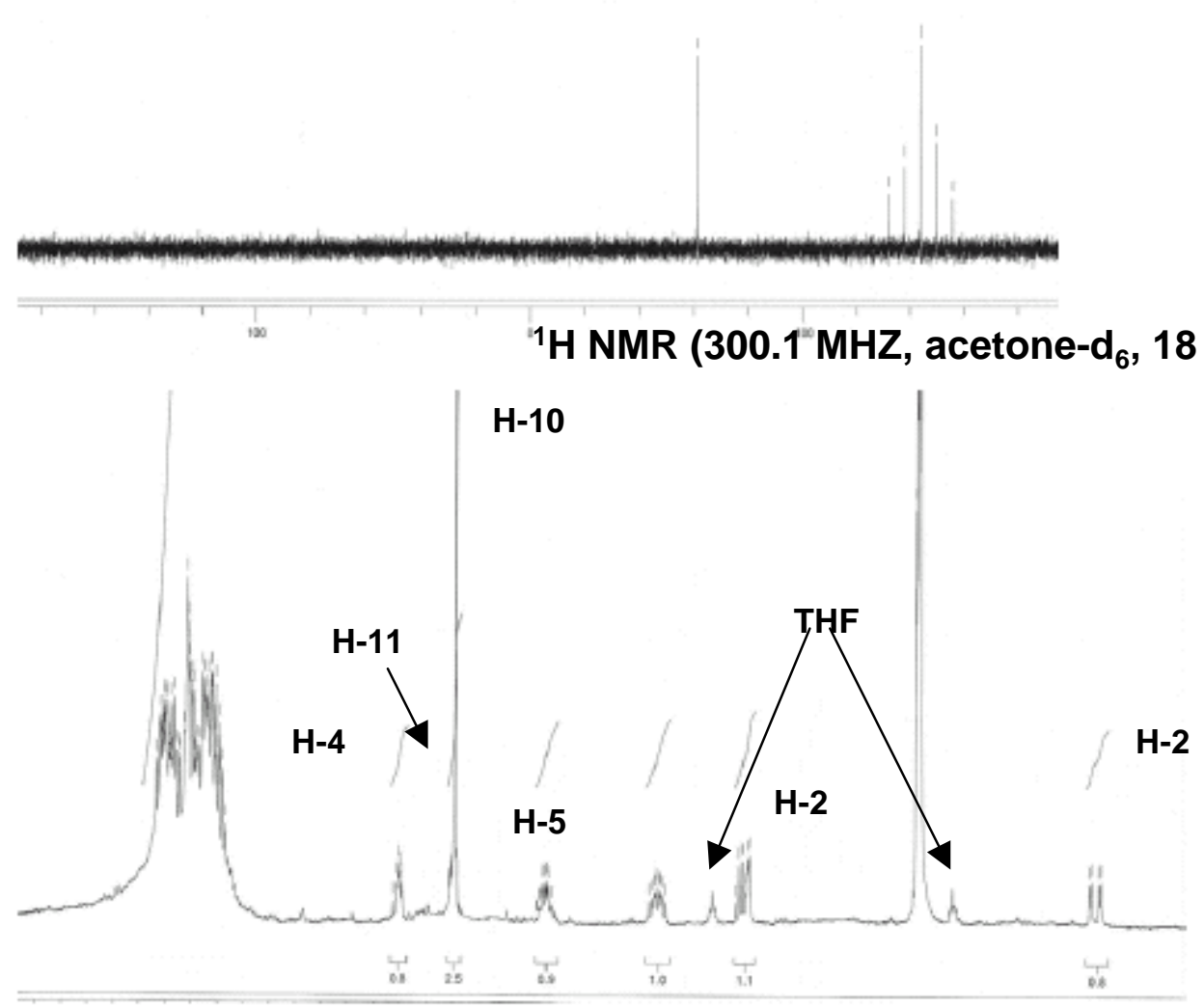




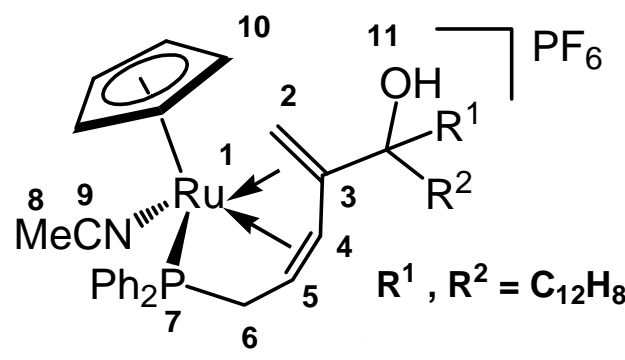

Complex 4
${ }^{13} \mathrm{C}\left\{{ }^{1} \mathrm{H}\right\}$ NMR $\left(100.6 \mathrm{MHZ}\right.$, acetone- $\left.\mathrm{d}_{6}, 18{ }^{\circ} \mathrm{C}\right)$ Acetone- $d_{6}$

C-2

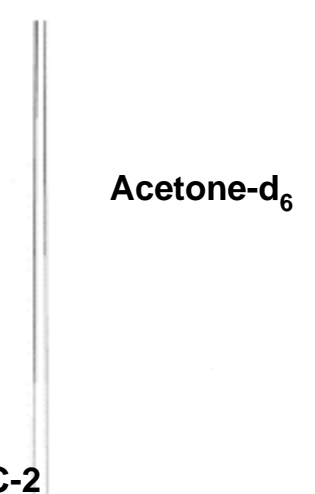

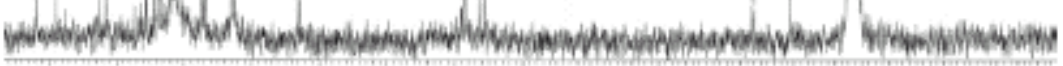
(n)

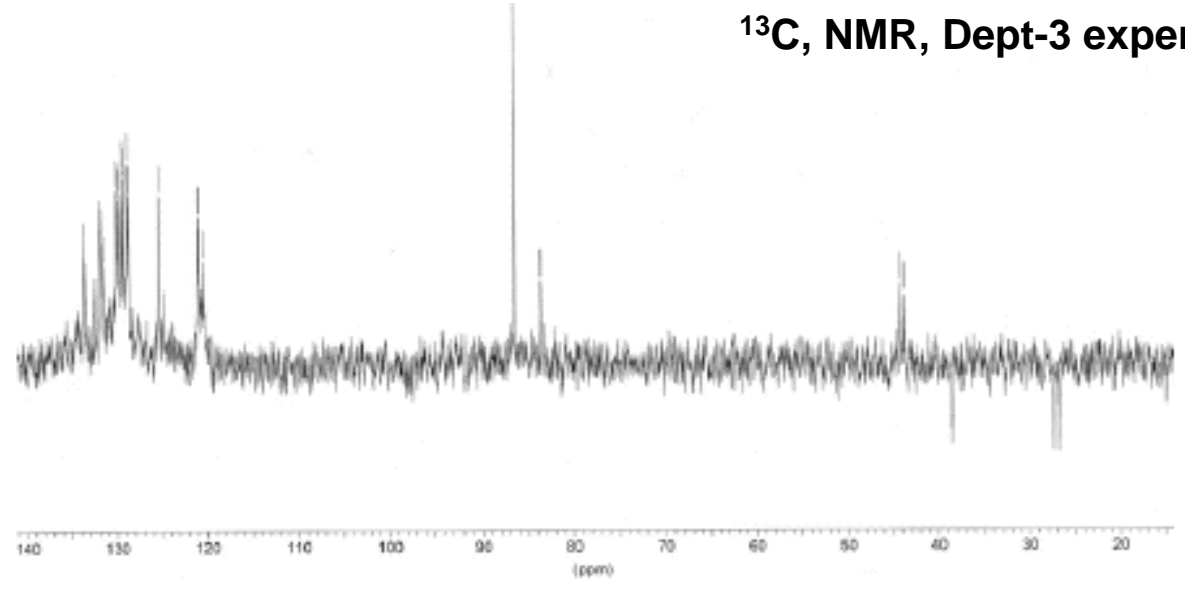




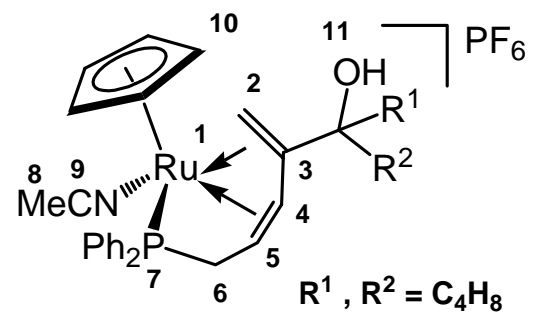

Complex 5
${ }^{31} \mathrm{P}\left\{{ }^{1} \mathrm{H}\right\}$ NMR (121.5 MHZ, acetone- $\left.\mathrm{d}_{6}, 18^{\circ} \mathrm{C}\right)$

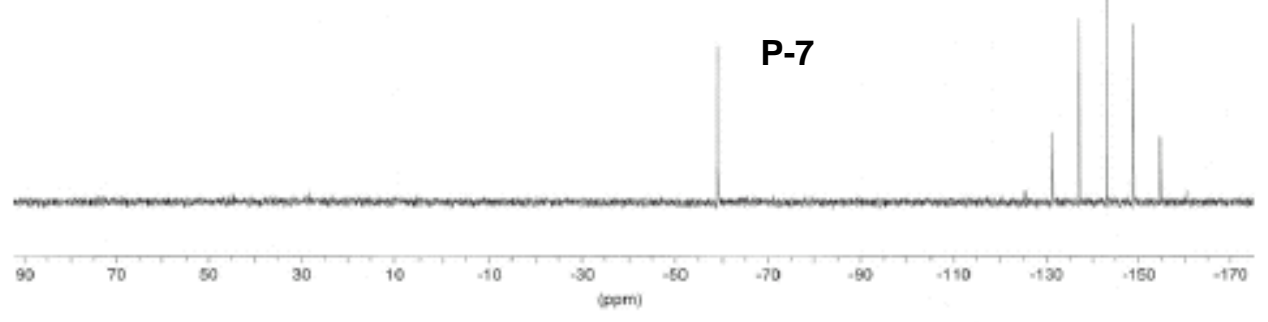

${ }^{1} \mathrm{H}$ NMR (300.1 MHZ, acetone-d $\left.{ }_{6}, 18^{\circ} \mathrm{C}\right)$

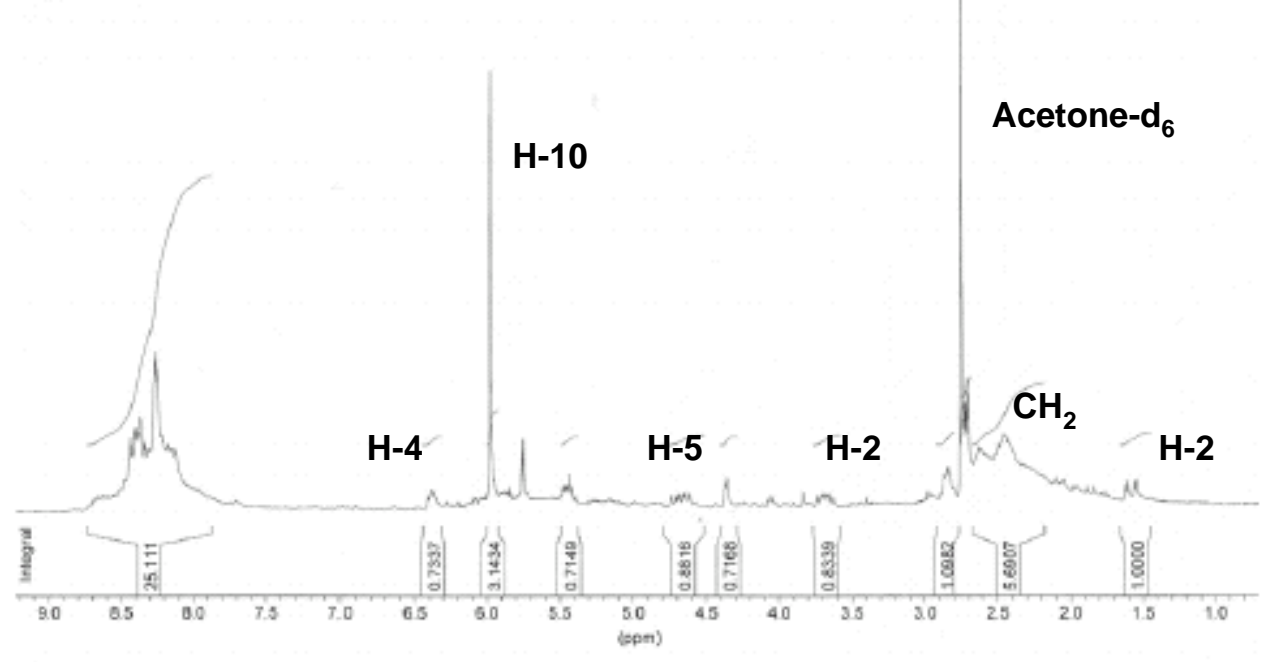




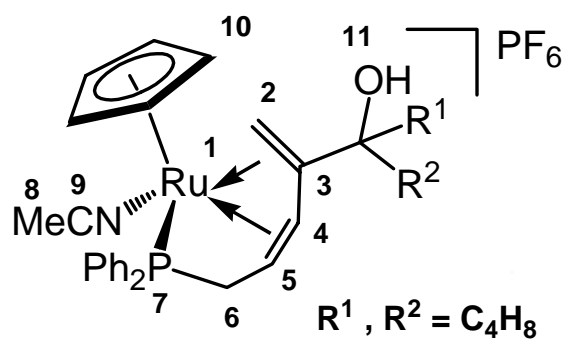

Complex 5

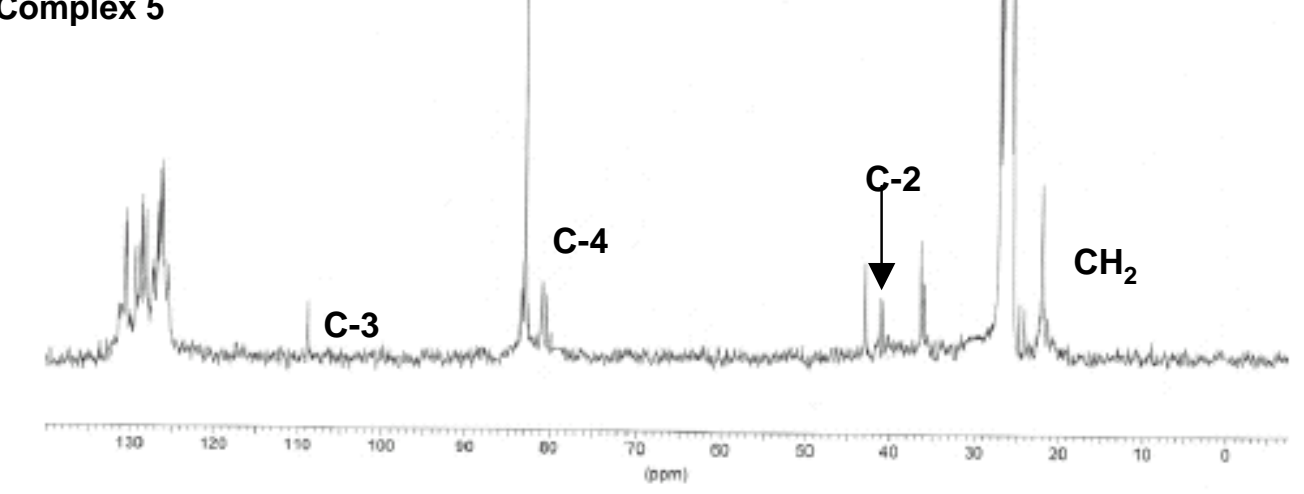

${ }^{13} \mathrm{C}$, NMR, Dept-3 experiment

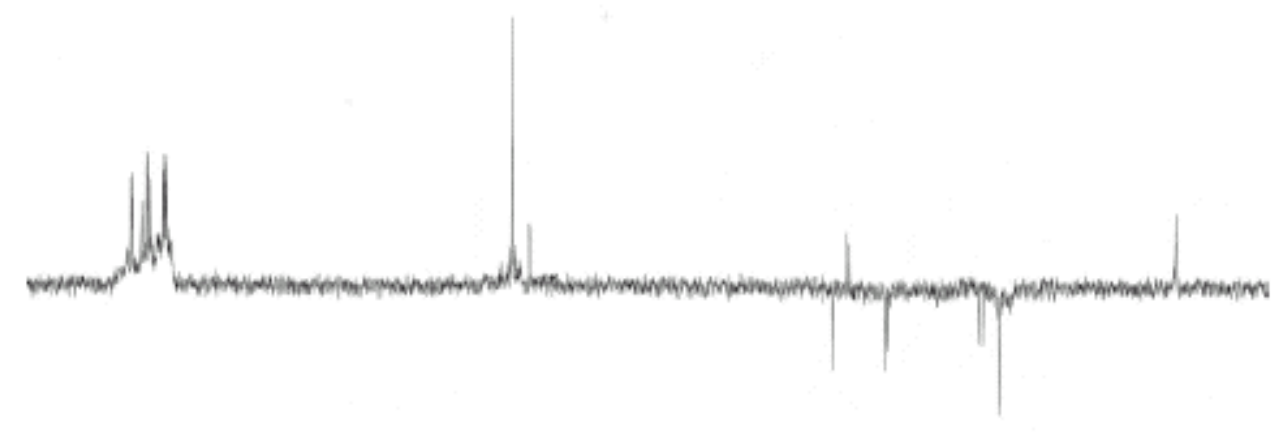

${ }^{13} \mathrm{C}\left\{{ }^{1} \mathrm{H}\right\}$ NMR (75.4 MHZ, acetone- $\left.\mathrm{d}_{6}, 18^{\circ} \mathrm{C}\right)$

\section{C-10}

Acetone-d6

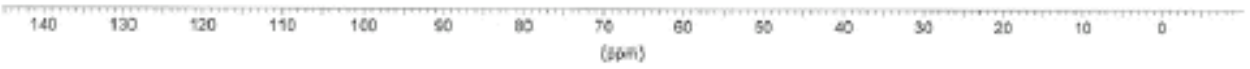




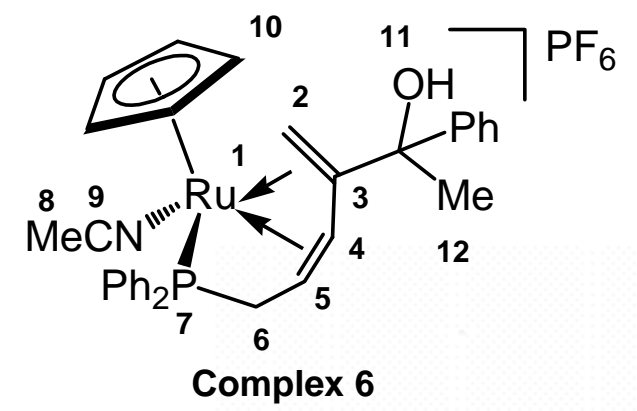

${ }^{31} \mathrm{P}\left\{{ }^{1} \mathrm{H}\right\}$ NMR (121.5 MHZ, acetone- $\left.\mathrm{d}_{6}, 18{ }^{\circ} \mathrm{C}\right)$
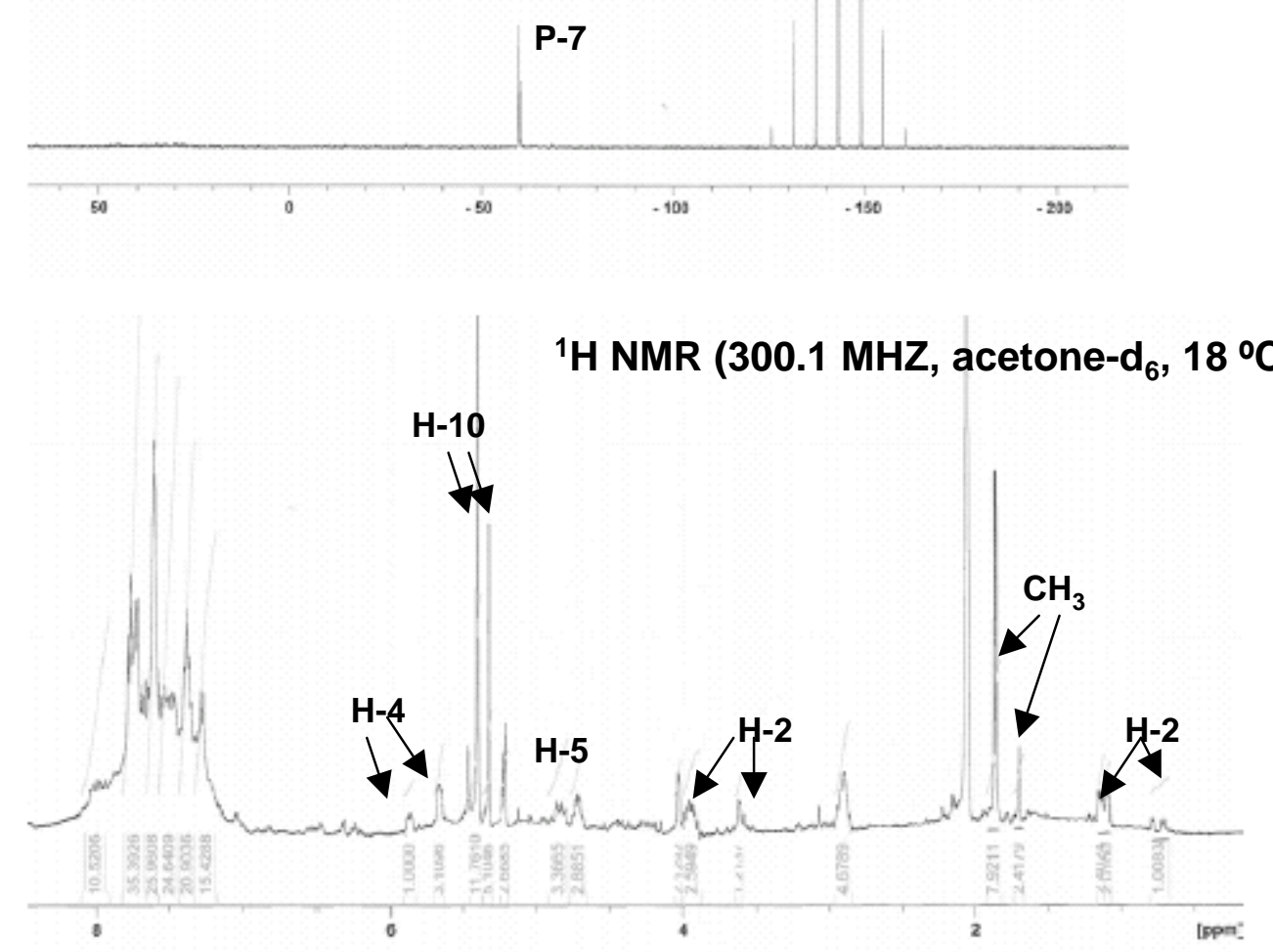


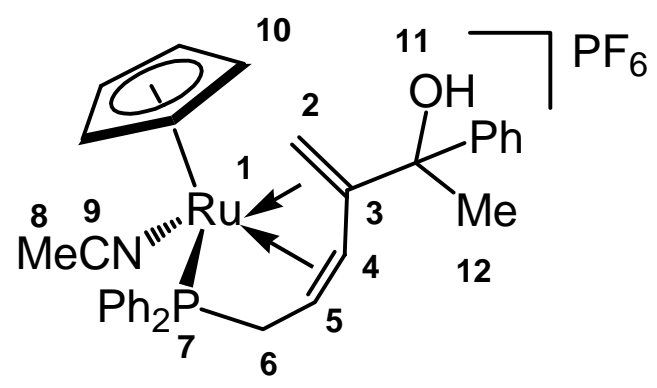

${ }^{13} \mathrm{C}\left\{{ }^{1} \mathrm{H}\right\}$ NMR $\left(75.4 \mathrm{MHZ}\right.$, acetone- $\left.\mathrm{d}_{6}, 18^{\circ} \mathrm{C}\right)$

\section{Complex 6}

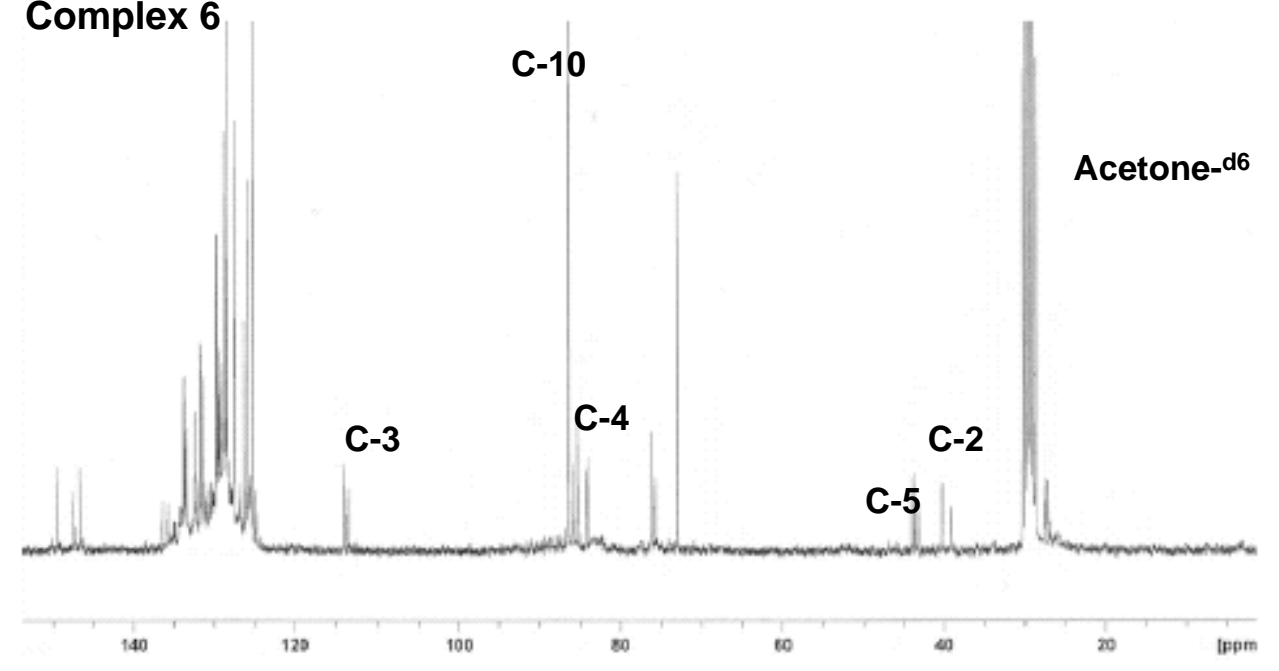

${ }^{13} \mathrm{C}$, NMR, Dept-3 experiment
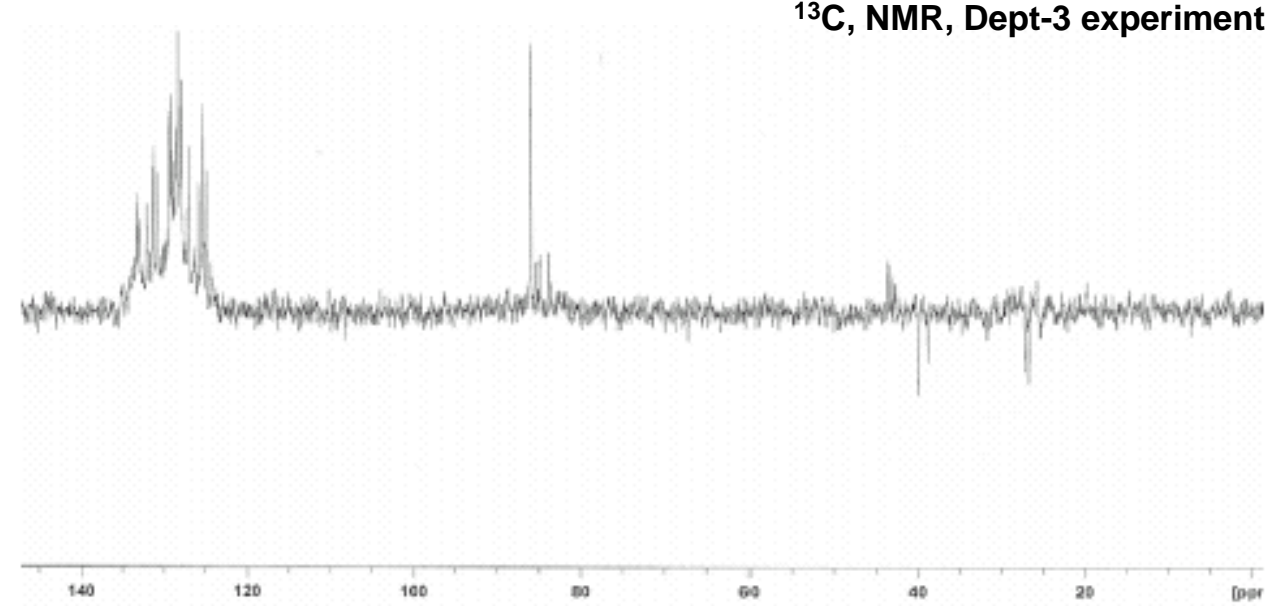